\title{
Crecimiento demográfico y formas de urbanización de las pequeñas ciudades en México
}

Demographic Growth and Patterns of Urbanization in Small Towns in Mexico

Crescimento demográfico e formas de urbanização das pequenas cidades no México

Aurélia Michel ${ }^{*}$

Antonine Ribardière*

Recibido: 31 de marzo de 2016

Aprobado: 24 de noviembre de 2016

Doi: http://dx.doi.org/10.12804/revistas.urosario.edu.co/territorios/a.4742

Para citar este artículo:

Michel, A. \& Ribardière. (2017). Crecimiento demográfico y formas de urbanización de las pequeñas ciudades en México. Territorios (37), 101-121. Doi: http://dx.doi.org/10.12804/revistas.urosario.edu.co/ territorios/a.4742

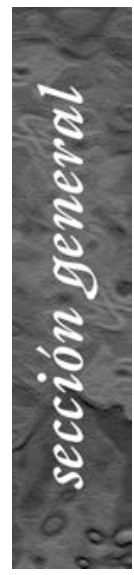

* Profesora titular, Universidad de Paris Diderot, parte de la Unidad Mixta del Investigación del Centre d'études en sciences sociales sur les mondes africains, américains et asiatiques (UMR CESSMA, por sus siglas en francés). Correo electrónico: aurelia.michel@univ-diderot-paris.fr ORCID: http://orcid. org/0000-0003-4574-3281

** Profesora titular, Universidad Paris I PanteónSorbona, parte de la Unidad Mixta de Investigación PRODIG (UMR PRODIG, por sus siglas en francés). Correo electrónico: antonine. ribardieve@univ-parisl.fr ORCID: http://orcid. org/0000-0002-8209-7007 
Palabras clave

Urbanización difusa, pequeñas ciudades, movilidad, rural-urbano.

Keywords

Extensive urbanization, small towns, mobility, rural-urban.

Palavras-chave

Urbanização difusa, pequenas cidades, mobilidade, ruralurbano.

tersitarias 37

102

\section{RESUMEN}

El artículo intenta identificar, en el caso de una región del sureste de México, las dinámicas demográficas, especialmente las formas de movilidad que alimentan el crecimiento de las pequeñas ciudades en México. Los procesos de urbanización se caracterizan por la debilidad de los recursos disponibles en términos de servicios y de empleo, incluso en términos de prestación de la vivienda. Sin embargo, entre los cuatro tipos de urbanización estudiados en este artículo, todos ellos tienen una importancia de intermediario: entre dos etapas migratorias, entre el espacio productivo rural y el mercado laboral urbano. De esta manera es como, mediante instalaciones en la periferia que pueden llegar a estar muy alejadas, en el límite de pequeñas ciudades las poblaciones encuentran un compromiso entre economías rurales familiares en decadencia y la dificultad de acceder a la ciudad y a sus recursos.

\section{ABSTRACT}

The paper seeks to identify the demographic trends, especially mobility, of the growth of small towns in a southeastern Mexico region. The urbanization processes observed are characterized by the limited resources available, not only in term of services but also in regards to employment or provision of housing. However, the four urbanization patterns observed in this paper play a bridging role between two chapters in migration stories and between productive rural area and urban employment market. It is in this way, by settlement far from the center, at the edge of small rural towns that families look for a compromise between the declining family farming and rural economies and the difficulty in accessing urban resources.

\section{RESUMO}

O artigo tenta identificar, no caso de uma região do Sudeste do México, as dinâmicas demográficas, especialmente as formas de mobilidade que alimentam o crescimento das pequenas cidades no México. Os processos de urbanização se caracterizam pela debilidade dos recursos disponíveis em termos de serviços e de emprego, inclusive em termos de prestação da vivenda. No entanto, entre os quatro tipos de urbanização estudados neste artigo, todos eles têm uma importância de intermediário: entre duas etapas migratórias, entre o espaço produtivo rural e o mercado laboral urbano. Desta maneira é como, mediante instalações na periferia que podem chegar a estar muito afastadas, no limite de pequenas cidades, as populações encontram um compromisso entre economias rurais familiares em decadência e a dificuldade de aceder à cidade e aos seus recursos. 


\section{Introducción}

La distribución del poblamiento en México siempre ha estado ilustrada por el peso de la capital. Hoy en día, son las ciudades que cuentan entre 500000 y 2 millones de habitantes las que experimentan el ritmo de crecimiento más rápido: $2 \%$ anual entre 2000 y 2010 (Garrocho, 2013). Sin embargo, el fenómeno urbano en México no debería reducirse a estas dinámicas metropolitanas: la trama urbana continúa densificándose y numerosas pequeñas ciudades — localidades $^{1}$ de más de 2500 habitantes - también registran tasas de crecimiento positivas. En regiones rurales, como el Estado de Oaxaca en el Sur del país, el peso relativo de las pequeñas ciudades está aumentando: mientras que en 1990, las localidades correspondientes a la franja de 10000 a 15000 habitantes agrupaban el $1,5 \%$ de la población total del Estado, en el 2010 concentraban más del 5,7\% en 2010. En el vecino Estado de Veracruz, es el conjunto de las pequeñas ciudades de 2500 a 10000 habitantes el que está viendo consolidar su peso relativo durante el mismo período ${ }^{2}$.

El crecimiento de las pequeñas ciudades depende de dos procesos principales. El primero es el de una urbanización difusa, que toma la forma de una dispersión cada vez más lejana y discontinua de las zonas metropolitanas, pero también de los polos urbanos regionales, así como de la construcción de vivienda a lo largo de los ejes de comunicación. El segundo es el desarrollo de localidades, sedes de la administración municipal (cabeceras o agencias municipales $^{3}$ ), que se han beneficiado de la descentralización administrativa iniciada por el Estado federal mexicano en los años 90. A partir del momento en que superan los 2500 habitantes, estas localidades se califican de urbanas en el censo de la población mexicano. No obstante, más allá del tamaño de la población aglomerada, conviene cuestionar la naturaleza del fenómeno urbano al que remiten estas localidades, que se caracterizan a menudo por la lejanía de los principales centros de empleos y por el déficit en materia de servicios y de acceso a las redes de infraestructuras y de comunicación.

Pese a la precariedad de los servicios urbanos disponibles, un cierto número de ciudades continúan atrayendo a nuevos habitantes, especialmente desde las zonas rurales pero también desde las zonas alejadas de la migración, al norte de México o a los Estados Unidos. Para entender este fenómeno, hay que admitir que estas pequeñas ciudades y sus periferias ofrecen recursos específicos, obviamente incompletos, pero que responden a las necesidades de las trayectorias sociales y migratorias de sus nuevos habitantes. Queremos, por ello, documentar y calificar los procesos de urbanización en curso en estas pequeñas localidades: por una parte, desde el punto de vista de los recursos urbanos a los que acceden los habitantes, especialmente los recién llegados para quienes se plantea esta cuestión de forma explícita y, por otra parte, desde el punto de vista de las formas urbanas producidas.
${ }^{1}$ El INEGI (Instituto Nacional de Estadistica, Geografía e Informática) define la localidad de la siguiente forma: lugar incluido en un municipio, ocupado por una o varias viviendas. Una localidad se considera rural cuando cuenta con menos de 2500 babitantes y no es cabecera del municipio (INEGI, 2010). El municipio designa la menor división politico-administrativa del territorio mexicano. Posee la cabecera (sede del municipio) y, en general, anexos, denominadas agencias municipales, que se encuentran bajo la responsabilidad de un representante electo.

${ }^{2}$ La franja de 2500 a 4999 habitantes pasa del 6,51 al 7,26\% de la población del Estado de Veracruz; la franja de 5000 a 9999 pasa del 6,6 al 6,9\%; la franja de 10000 a 15000 pasa del 3,7 al 4,9\% (INEGI, 1990; INEGI, 2010).

${ }^{3}$ Cf. nota 2.

\section{territarios 37}

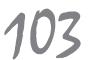


${ }^{4} 2406787$ en 2010 (INEGI, 2010).

territarios 37
Tanto en el plano de la dinámica demográfica como de la morfología de lo construido, proponemos mostrar aquí el carácter incompleto de estas urbanizaciones, $\mathrm{co}^{-}$ rrespondiente a situaciones sociales precarias y todavía por definir.

Concentramos nuestras observaciones en doce municipios de la región de Tehuantepec, ubicados en dos Estados del sureste mexicano (Veracruz y Oaxaca), que son representativos de las zonas rurales y periféricas de la región del istmo y en los que un cierto número de pequeñas ciudades registraron un crecimiento demográfico durante los últimos veinte años. En una primera parte, contextualizaremos la zona de estudio en la historia de su poblamiento para poder entender las dinámicas actuales, observando a partir del censo el origen de las poblaciones que han llegado recientemente y el destino de las poblaciones que han abandonado estas localidades durante el período reciente. Mostraremos que el crecimiento de las pequeñas ciudades y las formas de urbanización inducidas se inscriben en dinámicas de movilidad importante, especialmente en el sureste mexicano que actualmente se encuentra en un ciclo migratorio intensivo (Quesnel, Saavedra, \& Tallet, 2012).

A partir de datos recogidos en el trabajo de campo, abordaremos en una segunda parte las formas de urbanización de manera más cualitativa. El crecimiento urbano de las pequeñas ciudades hace referencia a cuatro formas típicas, identificadas al cruzar la morfología de la vivienda y de la trama urbana, las trayectorias de las poblaciones residentes y los recursos a los que acceden las poblaciones (en términos de vivienda, empleo e integración en la economía urbana o incluso de prestaciones sociales). De este modo podremos examinar el alcance de estas formas de urbanización para las poblaciones residentes. En particular, ¿̇los recién llegados acceden a servicios y pueden esperar una mejora de su nivel de vida? $\mathrm{O}$ al contrario, ¿son cautivos de sus dificultades de acceso a estos servicios y a los mercados laborales?

\section{El istmo mexicano en su trayectoria de poblamiento}

La región del istmo de Tehuantepec (figura 1), a caballo entre los Estados de Veracruz y Oaxaca, en el sudeste de México, tiene aproximadamente 2,4 millones de habitantes ${ }^{4}$. Incluye un alto porcentaje de población indígena, así como una serie de ciudades industriales en torno a la actividad petrolera y petroquímica que emplea a una gran parte de la mano de obra. Es a la vez ilustrativa de la trayectoria demográfica del conjunto del país y específica por el papel esencial de la industria petrolera en su desarrollo. Después de haber atraído durante varias décadas a una población migrante de la región y de todo el país, es hoy en día una zona de fuerte expulsión. Por ello, hay que analizar el reciente crecimiento de las pequeñas ciudades en una región todavía en movimiento en términos de poblamiento. 


\subsection{Dinámicas de poblamiento en el istmo en el siglo $\mathrm{XX}$}

A principios del siglo XX, la población indígena, ampliamente mayoritaria, se concentraba en esa época en el sur del istmo, en la parte de Oaxaca, especialmente en las ciudades de Juchitán y Tehuantepec, de población zapoteca. Con la construcción, a principios del siglo $\mathrm{XX}$, de una línea de ferrocarril que enlaza el puerto al océano Pacífico (Salina Cruz) con el puerto al mar Caribe (Coatzacoalcos), la región registra un crecimiento importante. Se desarrollan otras ciudades gracias al ferrocarril (Ixtepec y Matías Romero). La actividad de refinería de petróleo que se inicia en Minatitlán, cerca del puerto de Coatzacoalcos, crea

Figura 1. Mapa de localización

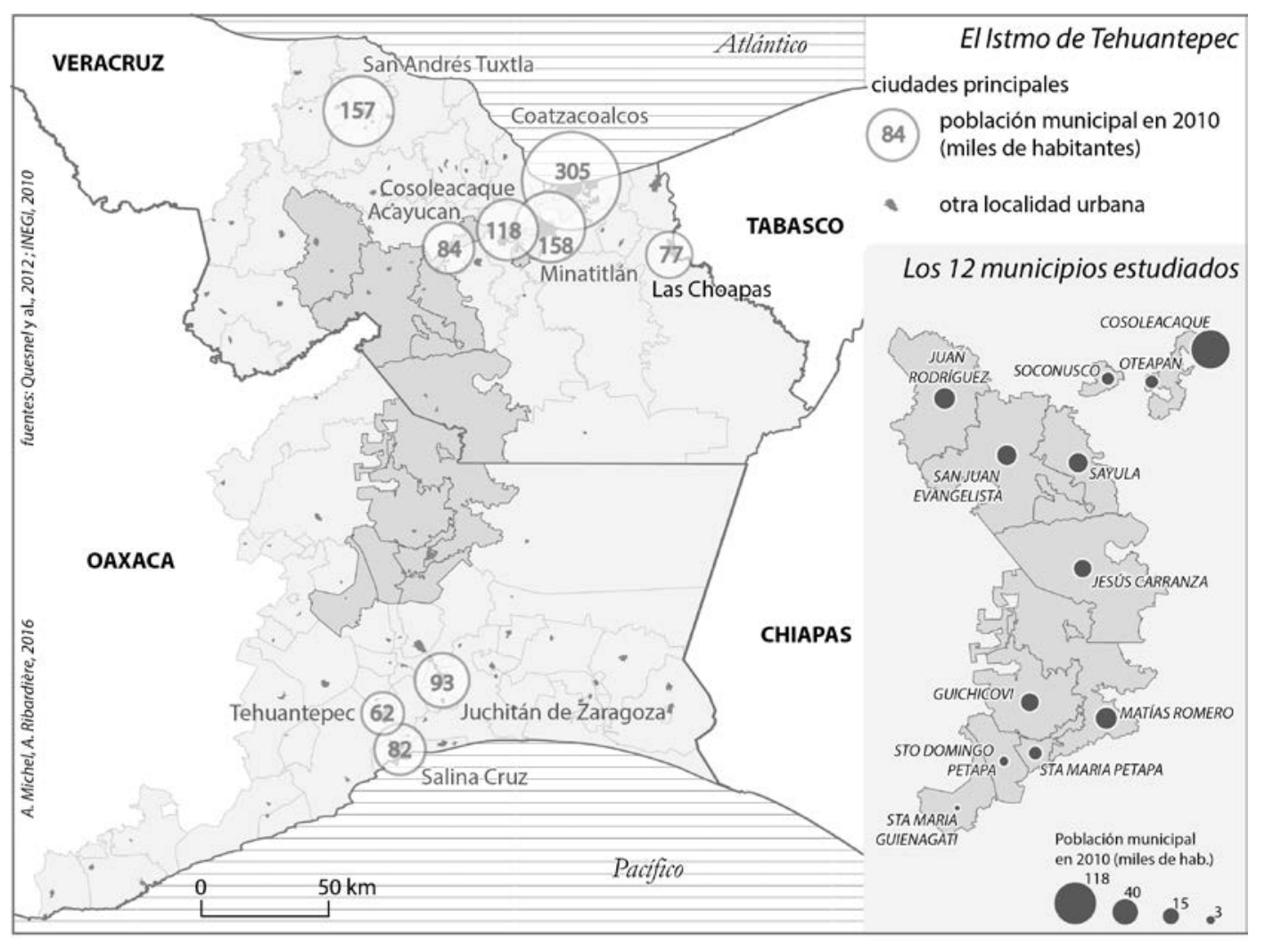

Fuente: Mapa elaborado por las autoras según datos de Quesnel et al, 2012 e INEGI, 2010. 
también una fuerte atracción. Mientras que, como en el resto del país, la población se multiplica por diez entre principios y finales del siglo XX, se pueden destacar dos fases intensas de este crecimiento.

Los años 1930 a 1940 constituyen el inicio de la transición demográfica en México, durante los cuales el desarrollo de la industria petrolera, pero también las consecuencias de una importante reforma agraria, se asocian con un fuerte crecimiento de la natalidad.

La siguiente fase, de los años 1960 a 1970, constituye el boom del crecimiento demográfico y sigue casi el mismo esquema: mientras que el crecimiento natural de la región experimenta ritmos elevados, las inversiones realizadas en los dos complejos petroleros portuarios y la implementación de un "corredor transístmico" por las políticas públicas atraen a una numerosa población regional y nacional a los extremos del corredor (Allub \& Michel, 1982). Al mismo tiempo, el istmo se ve afectado por diferentes aspectos de la política agraria mexicana: por una parte, se pone de nuevo en marcha la reforma agraria y se consolidan los focos de poblamiento rurales creados en los años 30; por otra parte, la Secretaría de Agricultura abre un frente de colonización en la región central del istmo, prioritariamente para actividades de ganadería bovina. Este frente de colonización atrae a familias de Estados vecinos y lejanos.

Estas dos políticas, agraria y petrolera, tersitarias 37 106 polos de urbanización al norte y al sur, hasta poder hablar de metropolización. Las ciudades de Minatitlán, Coatzacoalcos, pero también las ciudades secundarias vecinas (Cosoleacaque, Las Choapas), todas ellas muy metidas en la industria petroquímica y petrolera, constituyen una conurbación de 600000 habitantes. Al sur, una trama urbana bastante densa, entre las ciudades de Juchitán, Tehuantepec, Salina Cruz, Ixtepec y las ciudades secundarias reúne a 250000 habitantes. Entre ambas, las antiguas zonas rurales también se densificaron y el frente de colonización agrícola dio lugar a una multiplicación de los sitios de poblamiento. Dicho de otro modo, la multiplicación por diez de la población regional, que corresponde a las proporciones observadas para el conjunto de México, se traduce aquí en una fuerte concentración urbana en torno a la actividad petrolera por una parte y a una densificación de las zonas rurales por otra.

La ralentización del crecimiento de las metrópolis observado en otras partes de Latinoamérica (Souchaud \& PrévôtSchapira, 2014) tiene un equivalente en el istmo. El proceso aquí es todavía más marcado que al nivel nacional, porque está vinculado a la baja de las inversiones en la industria petrolera y la crisis relativa que experimenta el sector desde hace quince años. Además, los años 90 marcan el inicio de una fuerte emigración desde la región, tanto de las zonas rurales como de las ciudades industriales (Del Rey, Quesnel, \& Canales, 2006). 
Este nuevo contexto de fuerte expulsión de población de la región - especialmente en el Estado de Veracruz- afectó a las zonas rurales, pero también pesó sobre las tasas de crecimiento de las ciudades industriales más importantes (Minatitlán y Coatzacoalcos). Los centros petroleros registraron tasas anuales de crecimiento muy débiles en los períodos de 1995 a 2000 y de 2000 a 2005 , inclusive negativas, para retomar un ritmo moderado desde 2005 (entre el 1\% y el 1,7\% de crecimiento). En cambio, se registran tasas de crecimiento anuales significativas para las pequeñas ciudades, especialmente para las cabeceras de municipios rurales, cuya población se acerca a los 15000 habitantes: es el caso de Juan Rodríguez Clara, que después de haber experimentado una tasa negativa para el período de 1995 a 2000 , crece a un ritmo medio anual del $2,60 \%$ entre 2005 y 2010 (INEGI, 1990; INEGI, 2000; INEGI, 2010). El mismo esquema se observa con respecto a la cabecera de Oteapan o incluso en Sayula (Quesnel et al, 2012).

Estas diferentes etapas de poblamiento de la región son visibles a partir de un análisis de la estructura de la población por edad y lugar de nacimiento en tres tipos de localidades: los centros urbanos, las localidades periurbanas y las localidades en zona rural (Rodríguez et al, 2013). Los centros industriales (Minatitlán o Coatzacoalcos) se constituyeron a partir de los años 1950 por muy fuertes movilidades y han estabilizado su población desde 1990, pese a la señal de algunas partidas y retornos recientes. Las localidades periféricas, que están en el centro de nuestro cuestionamiento, dependen de una estructura cercana: se contabiliza el $81 \%$ de habitantes migrantes (nacidos en otro municipio) entre la población nacida antes de 1950, proporción que disminuye progresivamente al $70 \%$ para la población nacida después de 1980 . Pero más que los centros urbanos, las localidades periféricas siguen atrayendo a migrantes: todavía el $30 \%$ de los habitantes nacidos después de 1981 nacieron en otro municipio, sobre todo de la región o del Estado de Veracruz. Por último, estas localidades registran asimismo una población joven (nacida después de 1980) que nació en un $2,2 \%$ de los casos en la frontera norte, lo que revela probables retornos de migración de sus padres.

El poblamiento de las localidades en zonas rurales, más alejadas de los centros petroleros, es más local: el $60 \%$ de la población nacida antes de 1950 nació en la misma localidad. Pero de manera menos esperada, se constata que esta proporción no cambia mucho durante el siglo XX: los más jóvenes (nacidos después de 1995) nacieron tan solo en el $76 \%$ de los casos en su localidad de residencia. Ello significa que más del $20 \%$ del poblamiento de estas zonas rurales sigue estando constituido por migraciones, casi en su totalidad originarias de la misma región, exceptuando un 2,5\% de niños nacidos en la frontera norte. Dicho de otro modo: aunque la población de los polos urbanos parezca estabilizada, la región sigue estando atravesada por flujos migratorios de nivel regional y nacional. territarias 37

107 
${ }^{5}$ En el Estado de Veracruz: Juan Rodriguez Clara, San Juan Evangelista, Sayula de Alemán, Oteapan, Cosoleacaque, Soconusco y Jesús Carranza. En el Estado de Oaxaca: Matias Romero, Santo Domingo Petapa, Santa María Petapa, San Juan Guichicovi y Santa María Guevea de Humbolt.

${ }^{6}$ El municipio de Cosoleacaque cuenta asimismo con una localidad de más de 47000 habitantes: se trata, de hecho, de una parte de la trama urbana de Minatitlán que se desarrolló en el territorio del municipio de Cosoleacaque (esta localidad aparece registrada por otra parte con el nombre de "Minatitlán”).

${ }^{7}$ La única excepción es $M a$ tías Romero, que pierde 100 habitantes. Pero la zona urbana contigua, ubicada en otro municipio, registra importantes crecimientos.

\section{territarias 37} 108

\subsection{Crecimiento de las pequeñas ciudades en doce municipios del istmo}

Para comprender cómo se articulan procesos de crecimiento natural y migraciones para alimentar el crecimiento de las pequeñas ciudades, proponemos limitar el estudio a doce municipios que se extienden a lo largo de la carretera entre Salina Cruz y Coatzacoalcos ${ }^{5}$ (figura 1). Estos municipios centrales se caracterizan por ser menos urbanizados en contrasto tanto con el norte como con el sur de la región y ofrecen una gradación en cuanto a su proximidad a la carretera transístmica y a las grandes ciudades de la región. De municipios periurbanos a rurales, componen así una zona que nos permite recorrer una variedad de pequeñas ciudades y de crecimiento urbano. Para entender eventuales movilidades residenciales locales, vamos a observarlas al nivel de la localidad (cuando los datos del censo lo permitan). En 2010, se computan en estos doce municipios más de 1470 localidades, de las que 108 tienen más de 500 habitantes; entre estas últimas, veinticuatro constituyen oficialmente localidades «urbanas», por su papel de cabecera o porque cuentan con más de 2500 habitantes (figura 2A). De manera general, el semillero de localidades es más denso en la mitad norte de la zona; las ciudades de más de 10000 habitantes son más numerosas allí, dentro de las conurbaciones alrededor de los polos urbanos regionales: así ocurre con Cosoleacaque ${ }^{6}$, con más de 22000 habitantes y Oteapan, con cerca de 15000 habitantes (ambas alrededor de
Minatitlán) o incluso Sayula, con cerca de 14000 habitantes (cerca de Acayucan). Las demás ciudades de esta franja de tamaño están más aisladas: Juan Rodríguez Clara al oeste y Matías Romero al sur de la zona. El papel estructurante de la carretera en la repartición del semillero de localidades se muestra de forma nítida, especialmente cuando se considera el conjunto de las localidades: por ejemplo, una serie de aldeas, que reúnen a unas decenas o centenas de habitantes, bordea la carretera transístmica en las inmediaciones de Sayula (figura 2A). Por el contrario, la posición en relación con la carretera no parece influir en el crecimiento de las localidades.

Este crecimiento, observado en una parte entre los dos censos de 1990 y 2000 y posteriormente en otra entre los de 2000 y 2010 , sigue siendo modesto en toda la zona. De media, el crecimiento anual de las localidades de más de 500 habitantes no alcanza 0,5 puntos, ni entre 2000 y 2010 , ni durante el período precedente (1990 y $2000)$. Con todo, aparecen distintos perfiles (figuras $2 \mathrm{~B}$ y $2 \mathrm{C}$ ).

Entre 2000 y 2010 , todas las cabeceras municipales crecen ${ }^{7}$. Sayula, que figura entre las más dinámicas, gana así un 2,6\% de población por año, de media; la localidad de Santo Domingo Petapa, otro ejemplo de crecimiento en el sur, gana el 2,3\%.

$\mathrm{Al}$ norte de la zona, la proximidad a los polos urbanos regionales constituye otro factor de dinamismo. En particular, están registras nuevas localidades tanto en 2000 como en 2010, con nombres que remiten a modos de producción muy específicos: así, 
en Cosoleacaque, tres nuevas localidades en 2010 integran en su toponimia incluso el término de "fraccionamiento"; una nueva localidad también figura registrada en Soconusco con el nombre de Fraccionamiento Santa Cruz.

Por último, en los municipios rurales es donde son más numerosas las localidades en declive. En el municipio de San Juan Guichicovi, por ejemplo, tan solo la cabecera experimenta realmente un aumento de población entre 1990 y 2010 ; más al norte, en el municipio de San Juan Evangelista, cuya cabecera cuenta con apenas más de 4000 habitantes en 2010, un tercio de las localidades pierde población durante el periodo (entre $-0,3$ y $-1,3 \%$ de media entre 2000 y 2010).

De este modo, si bien el crecimiento demográfico es débil al nivel de la zona

Figura 2. Evoluciones demográficas, 1990-2010

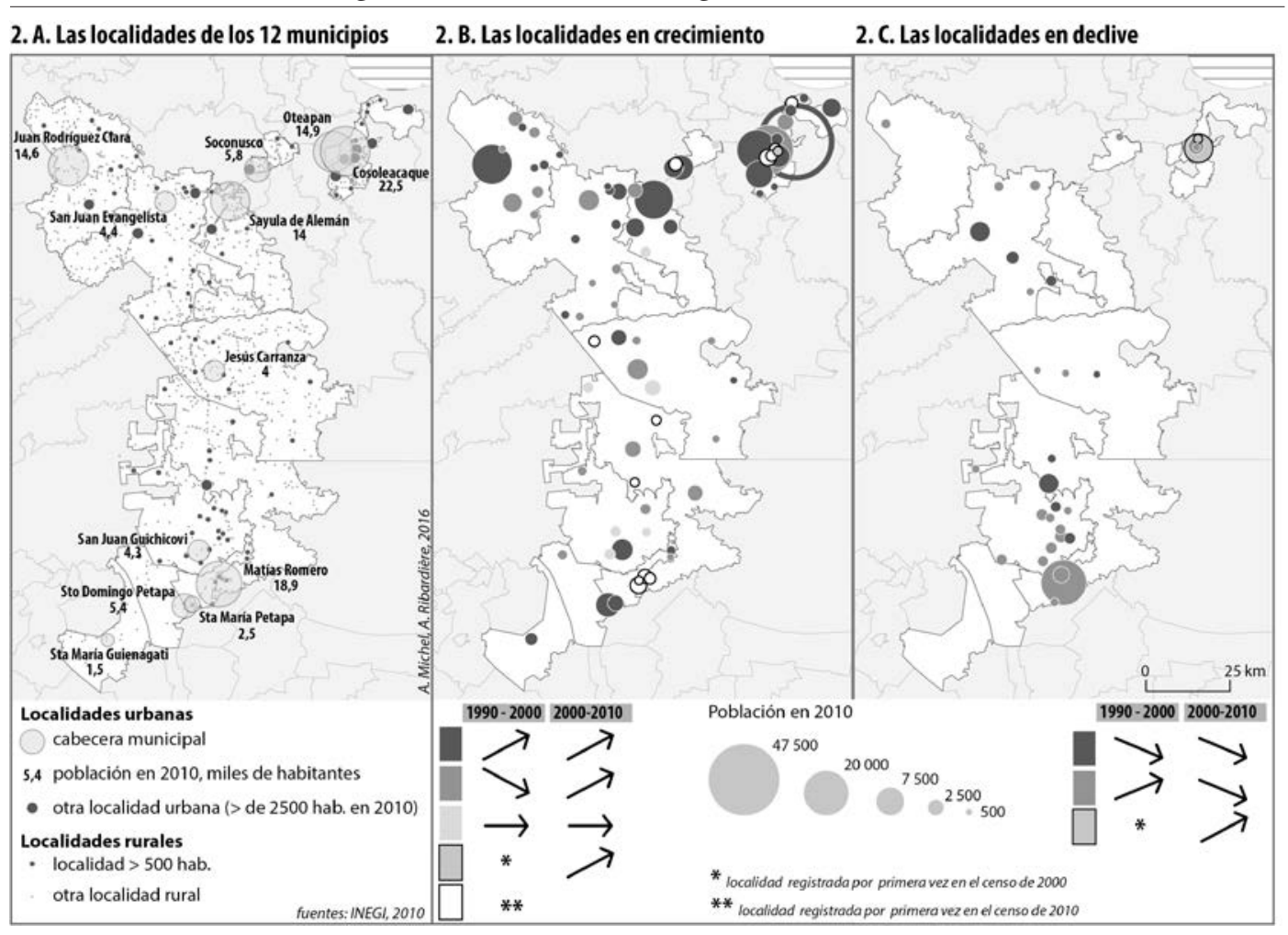

Fuentes: Mapa elaborado por las autoras con datos del INEGI, 2010. 
${ }^{9}$ De cinco años de edad $y$ más.

${ }^{10}$ El análisis de estas partidas no puede realizarse por correspondencia de elementos con el análisis de las llegadas, puesto que la muestra del INEGI no permite delimitar la emigración hacia los Estados Unidos.

\section{tersitarias 37} 110 observada, beneficia en primer lugar a las localidades urbanas. Este débil dinamismo no significa una inercia del poblamiento regional. La aparición entre dos censos de localidades correspondientes a urbanizaciones que contienen varias centenas de viviendas hace pensar, al contrario, en evoluciones rápidas de las formas urbanas y movimientos poblacionales no despreciables, por lo menos a nivel local inter e intra-municipal.

Se pueden entender en parte las migraciones recientes utilizando los archivos detallados (muestra) del censo. Permiten -al nivel del municipio únicamenteconfrontar el lugar de residencia de la población de cinco años y más en 2010, con el registrado en 2005. Los recién llegados representan una proporción del orden del 3 al $4 \%$ de la población residente ${ }^{9}$ en los pequeños polos urbanos tales como San Juan Guichicovi, Matías Romero o incluso Sayula. Su peso relativo aumenta en los municipios de pequeño tamaño: así, las aproximadamente 500 personas registradas en 2010 en Santo Domingo Petapa procedentes de otro municipio (o del extranjero) representan un poco más del $6 \%$ de la población residente. En dos municipios, los recién llegados representan más del $10 \%$ de la población registrada en 2010 : se trata de Cosoleacaque y de Soconusco, en los cuales han sido edificados nuevos fraccionamientos entre 2000 y 2010.

El análisis de la procedencia de estos migrantes recientes permite, en primer lugar, subrayar el peso de las movilidades residenciales de proximidad. Si se considera el Estado de donde proceden los residentes que llegaron desde 2005, Veracruz y Oaxaca constituyen juntas, de los doce municipios estudiados, el primer origen. Estas migraciones remiten a dos escenarios principales. El primero expresa los movimientos de desconcentración de los polos urbanos hacia sus periferias, que pueden ser espectaculares cuando su desconcentración se apoya en fraccionamientos (más de los $2 / 3$ de los recién llegados a Soconusco residían en 2005 en Acayucan) o más discretos cuando los modos de urbanización son más espontáneos (el $27 \%$ de los nuevos habitantes que llegaron a Santa María Petapa residían en 2005 en el municipio de Matías Romero).

El segundo escenario expresa los vínculos entre los municipios más rurales y los polos urbanos locales por una parte, $y$ los vínculos de estos polos locales con los polos urbanos regionales por otra parte (Coatzacoalcos en especial). Estos vínculos aparecen aún de forma más clara cuando ya no se consideran los nuevos habitantes que llegan, sino las partidas desde cada uno de los doce municipios estudiados ${ }^{10}$. Así, cerca de un cuarto de la población que salió de Matías Romero entre 2005 y 2010 hacia un destino nacional eligió su domicilio en el puerto industrial de Coatzacoalcos.

Al lado del peso de los flujos de proximidad, el análisis de la procedencia de los migrantes recientes permite distinguir otros cuatro orígenes: los Estados Unidos, la región de la frontera norte, la zona metropolitana de la Ciudad de México y, aunque con discreción, la península de 
Yucatán. Estos orígenes coinciden con los grandes esquemas de migración establecidos a nivel nacional (Sobrino, 2010) y pueden interpretarse como retornos desde los principales destinos de emigración ${ }^{11}$. Las migraciones hacia Yucatán, más recientes, aparecen claramente en el examen de las partidas. Estos esquemas migratorios se combinan de forma matizada según los municipios.

En la cabecera de Santo Domingo Petapa (figura 3 ) los 501 recién llegados en 2010 proceden, además de las inmediaciones (de la ciudad vecina de Matías Romero, pero también de la capital del Estado de Oaxaca), de la metrópoli de México en la proporción de un cuarto y más precisamente, un $20 \%$ tan solo del municipio de Naucalpan en el Estado de México, lo que sugiere cadenas de migraciones bastante construidas. La observación de las salidas certifica la perennidad de estos destinos: más de la mitad de la migración interna se dirigió, entre 2005 y 2010 , hacia el Estado de México o el Distrito Federal. Se encuentran, a través de este ejemplo, migraciones tradicionales entre Oaxaca y la capital del país. Se añaden a ello salidas más recientes hacia la frontera norte (los Estados de Sonora y de Baja-California) y los Estados Unidos, representando cada uno de ellos aproximadamente el $15 \%$ de las procedencias.

Otro esquema migratorio es el del municipio de Sayula en Veracruz (figura $3)$. El peso de los flujos de proximidad también aparece de forma muy nítida, tanto en el examen de las partidas como de las llegadas, especialmente en lo relativo a los polos urbanos regionales - Coatzacoalcos y Minatitlán-, pero también en las ciudades vecinas. La frontera norte domina las migraciones extra-regionales: es la procedencia de casi un cuarto de los que llegaron entre 2005 y 2010 , de los que más de la mitad vinieron de Ciudad Juárez en el Estado de Chihuahua donde se concentran las maquiladoras. Con todo, el análisis de la emigración hace pensar que a estos retornos no siguen nuevas partidas: ninguna fue registrada entre 2005 y 2010 , un efecto probable de la recesión económica en la industria manufacturera mexicana. Al contrario, el Estado de Quintana Roo, zona de desarrollo turístico, está ganando importancia: es el destino de más del $10 \%$ de la emigración extra-regional.

Para resumir, ¿qué cabe destacar de los diferentes censos a este nivel local? Los doce municipios corresponden a la periferia y al interior de una zona industrial en plena desaceleración. Actualmente es una zona de partida, en cualquier caso poco dinámica tanto en el ámbito económico como en demográfico. La particularidad de esta región reside en el crecimiento de las cabeceras municipales en detrimento de las zonas rurales y, de manera todavía más nítida, a favor de las ciudades situadas en la franja de 10000 a 15000 habitantes. Esta inercia aparente oculta, sin embargo, importantes movimientos internos: hacia la periferia de las mayores ciudades, y sobre todo articulados en circulaciones de gran distancia, hacia la ciudad de México, la frontera norte y los Estados Unidos
${ }^{11}$ Retornos a la región, pero no forzosamente allugar de nacimiento ni a la localidad desde donde salieron estos migrantes. 
12 El material utilizado procede de trabajo de campo efectuado en julio de 2014 en estas localidades, a partir de entrevistas realizadas a los responsables municipales y a los habitantes.

\section{tersitarias 37}

Figura 3. Dos sistemas migratorios

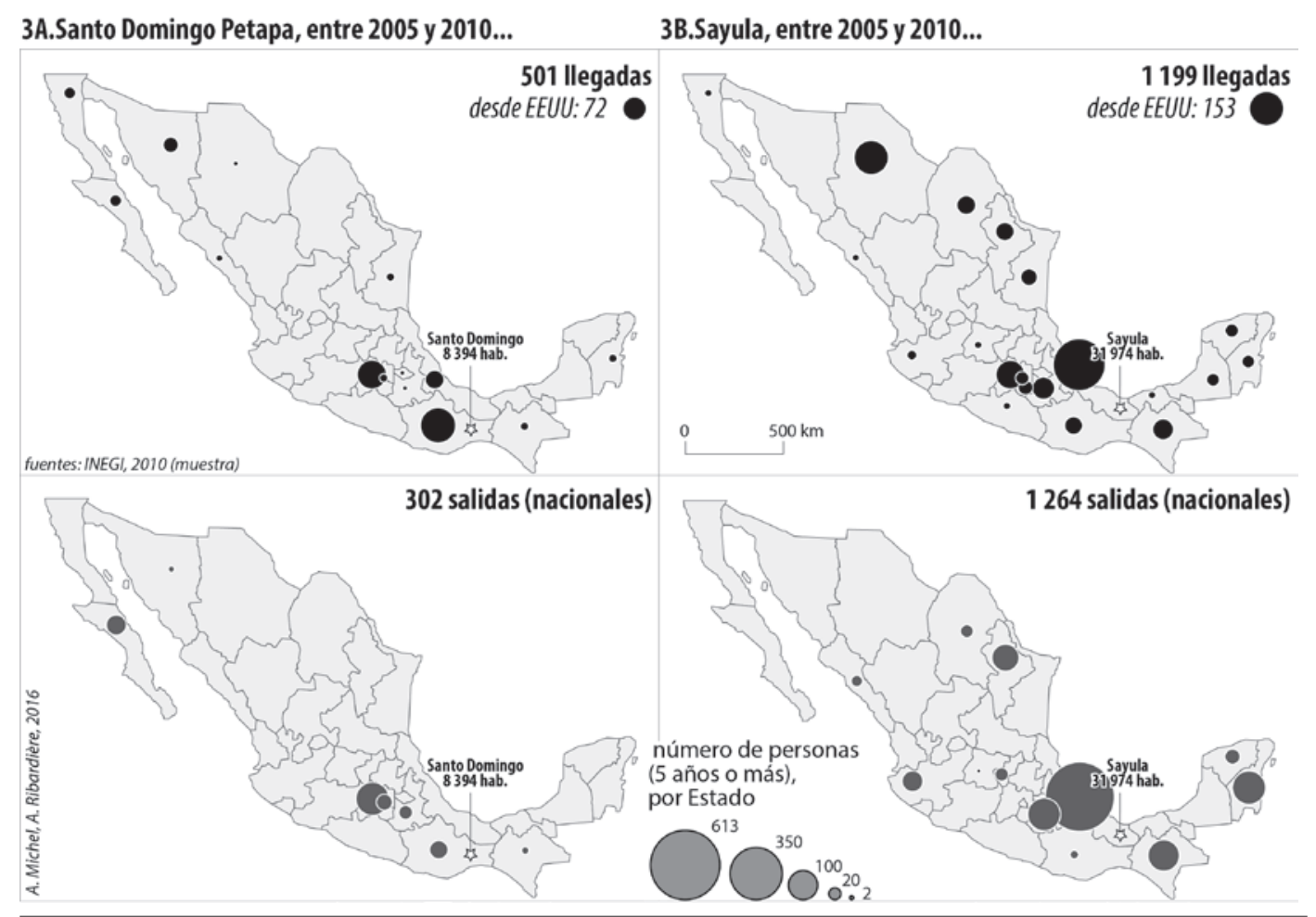

Fuentes: Mapa elaborado por las autoras según datos del INEGI, 2010.

principalmente, donde las posibilidades de empleos son mayores. Aunque el movimiento migratorio desde el campo sigue en curso todavía, estas pequeñas ciudades son hoy destinos de retorno, tránsito, partida.

\section{Formas y procesos del crecimiento urbano en las pequeñas ciudades}

Se trata ahora de documentar de forma más concreta la situación de las localida- des urbanas que han experimentado los mayores crecimientos desde 2005. Se han podido extraer cuatro situaciones típicas en la quincena de localidades visitadas. Se definen en función de la articulación de las formas de la vivienda, de la inserción o vínculo de estas nuevas viviendas con las tramas urbanas existentes, de las trayectorias migratorias de los residentes, y de los recursos urbanos codiciados y a los que aceden efectivamente los recién llegados ${ }^{12}$. 


\subsection{Fraccionamientos}

La forma más visible del crecimiento urbano es el surgimiento de fraccionamientos construidos por grandes grupos inmobiliarios nacionales. Grupos inmobiliarios como el grupo Roma que está implantado desde hace veinte años en Veracruz, se define a sí mismo como el promotor líder en la parte sureste de México y anuncia más de 20000 viviendas en la región ${ }^{13}$. Levanta en unos meses urbanizaciones que agrupan varias centenas de viviendas, en los municipios periféricos de las grandes ciudades. Los fraccionamientos están destinados a alojar a poblaciones de Minatitlán (fraccionamiento Los Mangos en el municipio de Cosoleacaque) o Acayucan (fraccionamiento Santa Cruz en el municipio de Soconusco), que van a aceptar alejarse de los centros de las ciudades para acceder a la propiedad. Estas formas de urbanización corresponden a los crecimientos más rápidos: se trata, de hecho, de la creación de nuevas localidades (véase figura $2 \mathrm{~B}$ ).

La particularidad de estas urbanizaciones es que están construidas en parcelas en total discontinuidad con la trama urbana existente, tanto en el caso de la periferia metropolitana como de la cabecera municipal. De hecho, estas construcciones están determinadas por oportunidades relativas a la propiedad de la tierra que no abundan en el contexto mexicano: el territorio de la mayoría de los municipios de la región está formado por ejidos (tierras colectivas inalienables atribuidas por la Secretaría de Reforma Agraria de 1930 a 1992). Desde la ley de 1992 que reforma la legislación agraria, los titulares de una parcela ejidal tienen la posibilidad de solicitar su plena propiedad y cederla (por venta o de otra forma), con la condición de que la asamblea del ejido y su consejo aceptaran el procedimiento de privatización. Ahora bien, los municipios vecinos de Minatitlán o de Acayucan son en su mayoría heredados de las comunidades indígenas (de lengua populuca), que han mantenido prácticas comunales relativas a la propiedad de la tierra. Son raros los ejidos que aceptan cambiar de régimen y aun cuando las parcelas son tituladas, la presión social del consejo ejidal puede ser muy fuerte. Así, a menudo "en medio de la nada", es donde los grandes grupos consiguen adquirir una parcela para su urbanización (figura 4). Sin embargo, las consecuencias de esta localización son pesadas, para los habitantes y para los municipios.

La urbanización Los Mangos, que acababa de ser ocupada en el momento del censo de 2010, se encuentra a dos kilómetros al sur de la ciudad de Cosoleacaque, apartada de la carretera que va hacia $\mathrm{Mi}$ natitlán. Las pequeñas casas individuales figuran entre las más baratas del mercado de interés social. Se proponen como acceso a la propiedad a los beneficiarios del Seguro Social ${ }^{14}$; se trata en este caso de trabajadores del comercio, pequeños funcionarios (policías, por ejemplo), chóferes de taxi, etc. A través de programas del tipo INFONAVIT o FOVISSSTE ${ }^{15}$, pueden esperar acceder a un crédito bancario para adquirir una vivienda de 300000 pesos de
${ }^{13}$ El grupo introduce en su sitio web una cronología de crecimiento espectacular. Se puede leer para el año 2008: "El grupo ROMA vendió la casa número 200000 del programa INFONAVIT en la urbanización de Soconusco, Veracruz".

${ }^{14}$ Es decir, todos los trabajadores permanentes o no que cotizan al sistema de seguridad social.

${ }^{15}$ El primero es el Instituto del Fondo Nacional de la Vivienda para los Trabajadores, institución de crédito $y$ de garantía hipotecaria destinados a los trabajadores mexicanos. El segundo es el Fondo de la Vivienda del Instituto de Seguridady Servicios Sociales de los Trabajadores del Estado, para los funcionarios.

territarios 37

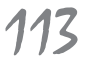


media (16000 euros, aproximadamente). Las casas de Los Mangos valen casi la mitad de las del Najantito, situado al borde de la carretera de Minatitlán, cerca de las infraestructuras en equipos (clínica, nuevo centro comercial) y de transportes. Al destinarse a las franjas más modestas de los trabajadores asalariados del sector formal, de los que la mayoría cobra un salario mínimo ( 80 o 90 pesos al día) y no trabajan todo el año, las viviendas son difíciles de vender, porque los créditos son difíciles de obtener, pese a las ayudas como las del programa INFONAVIT. Un tercio de las viviendas todavía estaba a la venta dos años después de finalizar las obras.

La mayoría de los habitantes de Los Mangos no dispone de automóvil particular. Hay que contar diez pesos para un taxi colectivo hasta Minatitlán, para un trayecto que puede durar entre 40 minutos y 1 hora. Dentro de Los Mangos, la posición con respecto a la carretera, a lo que hay que añadir un diferencial de calidad de la construcción, distingue claramente dos niveles de ofertas: las casas individuales a la entrada de la urbanización, los departamentos colectivos en la parte más aislada. En la zona que conecta ambas partes de la urbanización, dos tiendas atendidas por residentes ofrecen productos de alimentación y de limpieza básicos. Los habitantes están, por lo tanto, en una situación de encierro y de dependencia casi total con respecto al centro urbano vecino, en materia tanto de servicios públicos y comerciales, como tersitarias 37 de acceso al mercado laboral.
La misma lógica de oportunidad parece haber determinado la ubicación de la urbanización Santa Cruz, en el territorio del municipio de Soconusco, a 1,5 kilómetros de la cabecera (y a la misma distancia de las franjas de Acayucan).

Desde el punto de vista de las municipalidades, estos fraccionamientos corresponden a una aportación de población a la vez masiva y rápida, que puede sentirse como un secuestro cuando las finanzas locales se muestran insuficientes para responder no solo a las necesidades de los recién llegados, sino también para paliar los incumplimientos del promotor. Desde la cabecera de Soconusco (que reúne apenas a unos 6000 habitantes) un funcionario municipal explica que el municipio no tiene los medios para garantizar la gestión de la urbanización Santa Cruz (en la que residen más de 1600 habitantes en 2010). No solo el Grupo Roma no ha desarrollado las infraestructuras previstas (supermercado, iglesia, campo de fútbol), sino que una vez pasado el año de garantía, dejó a las autoridades locales la gestión de una urbanización con defectos patentes. Por ejemplo, el drenaje resultó ser insuficiente habida cuenta de la población residente. Inclusive cuando la implantación de fraccionamientos no cuestiona de forma tan radical los equilibrios locales, las autoridades municipales se muestran impotentes ante el promotor. El Plan de Desarrollo urbano de municipalidad de Cosoleacaque es un ejemplo de ello: las zonas de desarrollo consideradas no corresponden 
Figura 4. Carretera que lleva al Fraccionamiento Los Mangos, una nueva urbanización del grupo La Roma en construcción en medio de parcelas agrícolas

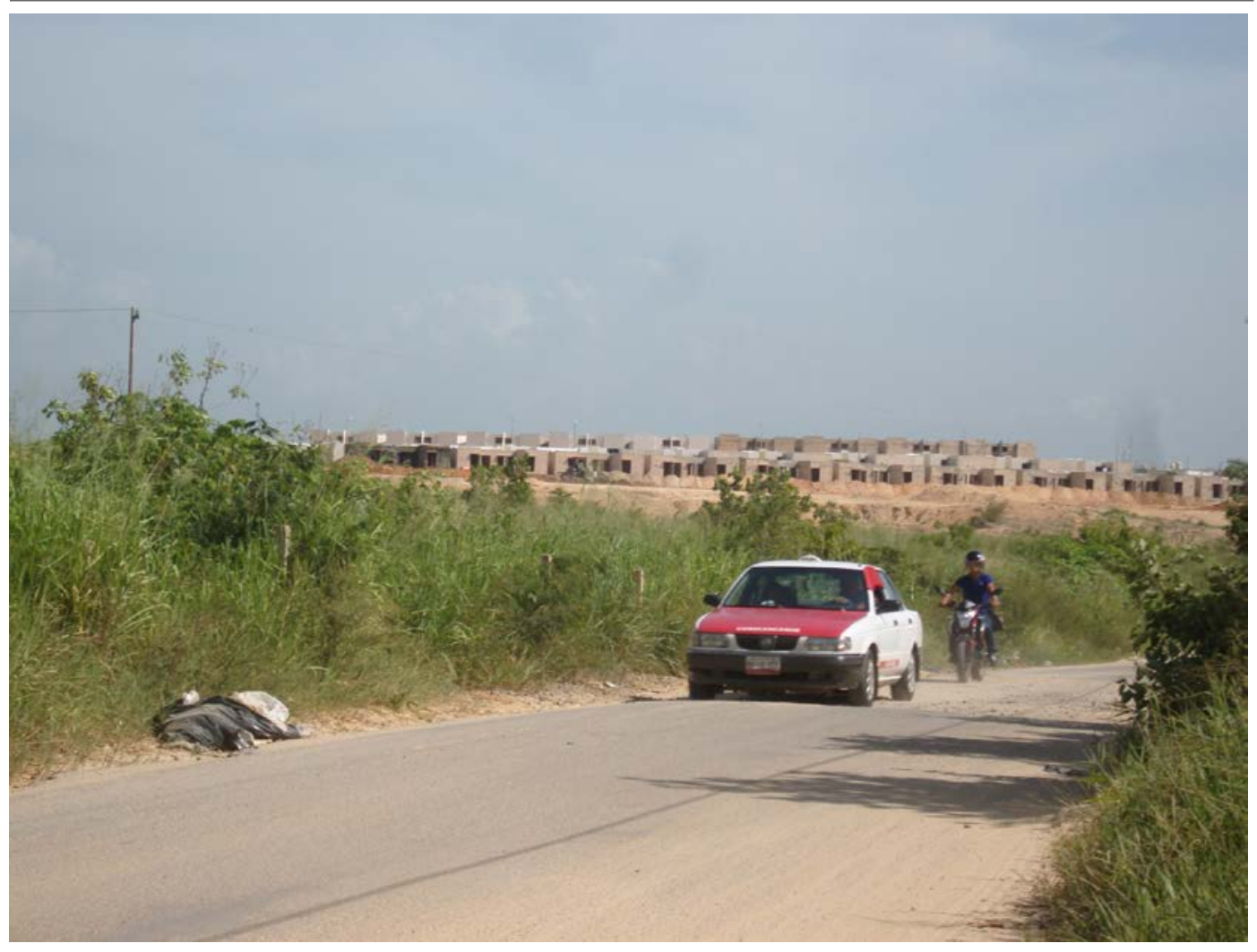

Fuentes: Elaboración propia, 2014.

con las localidades que registran efectivamente el crecimiento y los fraccionamientos en construcción no figuran en estos planes.

Desde el punto de vista de las poblaciones alojadas en estas urbanizaciones, acceden a la propiedad y a una vivienda con prestaciones mínimas (tres recámaras o habitaciones, cocina y cuarto de baño).
Sin embargo, en términos de recursos urbanos, pierden más bien con el cambio al mudarse a estas nuevas localizaciones: se alejan especialmente de los mercados laborales a pesar de que, debido a la precariedad de sus empleos, serían las poblaciones que tendrían más necesidad de estar conectadas a ellos. 
${ }^{16}$ Para un estudio reciente de los procesos de regularización, a partir del ejemplo de las periferias de la ciudad de México, véase Valette, 2014.

17 Otra forma de propiedad social en México: tierras colectivas protegidas por la Reforma Agraria y teóricamente inalienables.

\section{territarias 37}

\subsection{Crecimiento “espontáneo" en la periferia de las pequeñas ciudades}

Además de los fraccionamientos, los municipios periféricos de los polos urbanos regionales experimentan también un crecimiento en forma de instalaciones irregulares. La compra de una parcela en las franjas urbanas implica acuerdos informales que permitirán eventualmente una regularización posterior por el municipio (Clichevsky, 2008 $)^{16}$. Parece obvio que para ciertos municipios es preferible reconocer estas adquisiciones ilegales antes que ver la instalación de miles de viviendas de golpe en una parcela que no podrá conectarse fácilmente a la red. Así, un funcionario municipal del municipio de Oteapan explica cómo un proyecto de fraccionamiento del Grupo Roma se vio confrontado al rechazo por parte de los ejidatarios de vender las parcelas codiciadas. Las tierras ejidales parecen aquí cerradas a los grandes promotores externos (la presión urbanística también es menos fuerte que en el municipio vecino de Cosoleacaque).

Eso no impide que este crecimiento urbano, que puede calificarse de "espontáneo" en relación con los fraccionamientos comercializados por los promotores, plantee problemas de gobernanza específicos. Además de la cuestión de la regularización, la dispersión urbana traspasa las fronteras municipales, lo que induce, de hecho, una desigualdad de trato entre las poblaciones residentes según el municipio del que dependen.
El ejemplo observado en el municipio de Santa María Petapa ilustra estos casos de embrollos administrativos. La ciudad de Matías Romero se desarrolla en parte en un territorio que no gestiona ella, el del municipio de Santa María Petapa, lo que explica que la localidad de Matías Romero, a pesar de su desarrollo, registra una tasa negativa de crecimiento en el periodo más reciente (figura 2C). Ahora bien, resulta que la consolidación de las instalaciones irregulares en las tierras comunales ${ }^{17}$ (asfaltado de las vías, traída de agua y drenaje, electricidad) se efectúa según ritmos mucho más rápidos en las localidades dependientes del municipio de Matías Romero, cuyos recursos financieros son incomparables a los de Santa María Petapa.

En cambio, la organización de las redes de transportes, que dependen de lógicas privadas, superan con mayor facilidad las fronteras administrativas: los autobuses que comunican las localidades de Santa María pertenecen a una compañía privada, basada en Matías Romero.

El crecimiento de estas localidades periféricas se nutre de varios movimientos. Además del crecimiento natural, las migraciones de las inmediaciones son importantes: más de un cuarto de los recién llegados entre 2005 y 2010 al municipio de Santa María Petapa provienen del municipio vecino de Matías Romero. Estas afueras de Matías Romero son también las zonas donde se establece una población que circula entre varios mercados laborales. Así Antonieta, responsable de la 
agencia municipal de Rincón Viejo, nació aquí. Después de trabajar como contable en Puebla y luego en Ciudad de México durante más de quince años, «regresó» para cuidar a sus padres enfermos. Trabaja de vez en cuando como profesora y su marido, originario de la Zona Metropolitana de la Ciudad de México, no ha encontrado trabajo en esta pequeña ciudad. Evocan un proyecto de volver a la metrópoli.

En el límite de la dispersión urbana, las formas de la vivienda reflejan otras dinámicas. Es, de hecho, en estas colonias recientes donde se encuentran rastros de una migración de larga distancia. En la colonia de Puma Rosa, al norte de Matías Romero, las últimas casas antes de los campos o el bosque son simples casa de lámina, donde se alojan recién llegados de Chiapas que se benefician más o menos de las posibilidades de empleo en el pequeño comercio informal en la ciudad o como jornaleros agrícolas. Estos habitantes que han llegado recientemente, a veces de lejos o que quizás ya se han marchado o regresado, constituyen una población frágil que intenta acceder al débil mercado urbano y rural del municipio. La localización en los bordes de estas pequeñas ciudades es un compromiso geográfico razonable: una vivienda accesible, sino por derecho al menos de hecho, y la posibilidad de captar oportunidades de trabajo como jornaleros (en la construcción o en las infraestructuras de las vías públicas, trabajos agrícolas, limpieza en los comercios del centro, etc.). En la colonia vecina de Progreso, al contrario, las últimas casas reflejan de forma a veces ostentosa los medios de los propietarios: se adivinan aquí fondos procedentes de la migración hacia los Estados Unidos.

Al contrario del semillero de localidades a lo largo de la carretera transístmica, formado hace unos veinte años, que ya no retiene a la población, estas periferias conocen las tasas de crecimiento más importantes de la zona estudiada. Al mismo tiempo, estas localidades en crecimiento siguen siendo lugares de expulsión hacia los centros regionales, el norte del país y los Estados Unidos. Este crecimiento no significa, sin embargo, una "urbanización terminada" para la población concernida, especialmente en materia de acceso a los servicios y a las redes y el carácter inacabado de la urbanización es todavía más fuerte cuando la ciudad crece hacia un municipio distinto, que generalmente no puede asumir esa dispersión. Como si fuera un reflujo en segundo plano de las movilidades clásicas hacia los principales mercados laborales, polos industriales y metrópolis, la dispersión de las pequeñas ciudades parece la sombra de un éxodo rural que sigue todavía en la región.

\section{3 "Pueblotes" rurales en crecimiento}

Un cierto número de pequeñas localidades, que cuentan aproximadamente con 2500 habitantes, también han experimentado crecimientos notables en el último periodo censal. Es, en primer lugar, su función de tersitarios 37

117 
18 Se entiende aqui "pueblo" como primer nivel de la jerarquía urbana, justo antes de la pequeña ciudad.

${ }^{19}$ Programa representativo de las politicas sociales desde 1992, destinado a las madres de familia para la financiación de la escolarización de sus hijos (Bey, 2008)

\section{territarias 37} 118 pueblo - más que ciudad ${ }^{18}$ - la que explica su dinamismo demográfico.

Así La Cerquilla, con 2539 habitantes y ubicado en la carretera de Acayucan hacia Tuxtepec en el municipio de San Juan Evangelista (en su mayoría rural), parece un interfaz entre las comunidades campesinas y la administración pública. En particular, a la agencia municipal es a la que se distribuyen cada dos meses las subvenciones del programa Oportunida$\mathrm{des}^{19}$. Con este motivo tiene lugar un gran mercado de productos de consumo básico (ropa, materiales sociales y domésticos) que crea una actividad comercial temporal, pero de vital importancia para los localos. Este mismo mercado acompaña todas las distribuciones de Oportunidades, por ejemplo en Aguilera, agencia del municipio de Sayula situada en la carretera y también en crecimiento.

No obstante, esta función de pueblo no garantiza por sí sola el dinamismo demográfico de la localidad. La población de La Cerquilla se beneficia asimismo de la proximidad de un polo de empleo, en este caso un arenal. Según un esquema próximo es como se puede interpretar el dinamismo de la cabecera de Santa María Petapa, con 2322 habitantes, de la que dependen las localidades de la periferia de Matías Romero. Situada a $10 \mathrm{~km}$ de la carretera y a 18 $\mathrm{km}$ de Matías Romero, la localidad debe su estabilidad demográfica a las funciones asociadas a su estatuto administrativo, pero también a la proximidad de la cementera Cruz Azul: aproximadamente 200 activos de la localidad trabajan en ella.
Aunque con un peso demográfico más importante, la localidad de Sayula puede acercarse al funcionamiento de una cabecera rural. Situada en un cruce estratégico de la carretera, Sayula es una ciudad indígena de 13980 habitantes, entre los más antiguos sitios de poblamiento de la región. La población también ha aumentado (la parte del crecimiento natural es más importante en ella que en las demás localidades en crecimiento), pese a numerosas salidas para las zonas de migración extra-regional (Estados Unidos, Ciudad Juárez o Cancún). La fabricación de la carne pimentada, producto tradicional que se consume en el sur de Veracruz, continúa empleando a una buena parte de la población activa. También se constata una fuerte actividad a lo largo de la carretera. Una parte de la población va a trabajar en los centros petroleros vecinos y, en este caso, regresa solo el fin de semana.

En este caso es en el dinamismo de las actividades rurales donde se basa el crecimiento de las pequeñas ciudades del frente de colonización agrícola. Las funciones de ciertas agencias casi están exclusivamente dedicadas a la actividad local: el cultivo intensivo de piña en Los Tigres (municipio de Juan Rodríguez Clara), la ganadería bovina en Nuevo Morelos (municipio de Jesús Carranza). El crecimiento de estas actividades agro-comerciales se acompaña de una jerarquía social muy marcada, entre los propietarios de los medios de producción y los jornaleros, que se expresa directamente en la calidad de las viviendas (desde la casa de lámina carente de cualquier equipa- 
miento hasta la casa de planta baja y primer piso, construida con materiales de calidad (piedra), totalmente amueblada, delante de la que se aparca un vehículo de marca).

El dinamismo de ciertas localidades es tal que estas se encuentran en posición de competencia con la cabecera municipal. Así, la cabecera de Rodríguez Clara se beneficia del éxito del cultivo de la piña, o más bien depende de él: el municipio está dirigido actualmente por las familias políticas originarias de la agencia de Los Tigres, quienes oponen con total comodidad su modelo de desarrollo a las costumbres más tradicionales del resto del municipio. Esta oposición abarca el origen del poblamiento de estas pequeñas ciudades: por un lado la cabecera, antigua e indígena y, por otro, las aldeas convertidas en casi ciudad, con poblamiento más reciente, vinculado al frente de colonización agrícola.

En todos estos “pueblotes” la dinámica de crecimiento hace hincapié en el papel de interfaz o conexión que asume la localidad: interfaz económico, pero también administrativo como cabecera, hasta interfaz físico cuando la localidad se ubica en la carretera. No obstante, el crecimiento demográfico no implica verdaderamente el desarrollo de nuevos servicios, o de nuevas actividades, limitando en ello el alcance del proceso de urbanización.

\subsection{Pueblos en la migración}

Podría efectuarse la misma constatación a propósito del pueblo Santo Domingo Petapa (5429 habitantes). También se beneficia de la proximidad con la cementera Cruz Azul: cerca de 500 activos trabajan en ella. En este municipio indígena (zapoteca), todas las localidades rurales del municipio pierden habitantes durante el período, al mismo tiempo que se abandonan las actividades agrícolas (cultivo de la fruta o del maíz). La cabecera, la única localidad en crecimiento, resulta ser el lugar de un tipo de recurso bien específico, ligado a los sistemas migratorios. Se encuentra en el ejemplo de Santo Domingo Petapa el arquetipo de la comunidad indígena de Oaxaca, que se organiza en una migración colectiva (figura 3). Los vínculos con el pueblo de origen permanecen perennes y se materializan no solo con retornos anuales con motivo de la fiesta del pueblo, sino también de mayor duración. Así, Beatriz, que trabaja actualmente en el ayuntamiento y que nació en Naucalpan (Estado de México) en 1989, está de regreso en Santo Domingo desde hace dos años. Su madre, que sigue en Naucalpan, pasó diez años en los Estados Unidos y una de sus hermanas está casada con un estadounidense. El mismo fenómeno se encuentra en el municipio de Santa María Guienagati: redes migratorias estabilizadas hacia la ciudad de México, el norte y los Estados Unidos, declive de todas las localidades rurales y crecimiento de la cabecera municipal ${ }^{20}$ que concentra los recursos migratorios.

\section{Conclusión}

El crecimiento de las pequeñas ciudades observadas en el istmo de Tehuantepec
${ }^{20}$ Para un análisis del papel del anclaje local en las trayectorias migratorias de los migrantes indigenas, véanse los trabajos de Perraudin (2013). 
aparece como un eco de las movilidades de las poblaciones que han producido el crecimiento urbano de la segunda mitad del siglo XX en México. Continúan beneficiándose de las aportaciones vinculadas a las dinámicas migratorias desde el campo, de corto o de gran alcance, al recibir en sus márgenes a poblaciones que intentan acceder a las posibilidades de empleo ofrecidas tanto por el medio rural como por el urbano. Las propias pequeñas ciudades surgieron como puntos de partida y de retorno. Las recientes llegadas que alimentan su crecimiento muestran estos vínculos de gran alcance hacia los polos de empleo (Ciudad de México, Estados del norte o Estados Unidos).

Las consecuencias de estos movimientos conducen en gran medida a "espesar" la trama urbana existente aunque, en realidad, las formas urbanas y los espacios producidos dependan de lógicas bastante diferentes. No corresponden a las mismas poblaciones, no se apoyan en los mismos recursos locales (recursos productivos del interior rural, mercado - débil- del empleo urbano, mercado de la vivienda y prestaciones asociadas). Sin embargo, el proceso de urbanización se limita siempre a la producción únicamente de espacios residenciales.

En cada uno de los tipos observados, se constata un déficit de servicios, de acceso a las redes urbanas, a los mercados laborales, que justifica la hipótesis de una infraurbanización. El atractivo de las cabeceras, pero también de las pequeñas localidades urbanas muestra que se trata, sin embar- go, para los recién llegados, de acceder a nuevos mercados laborales, a recursos urbanos mínimos y, sobre todo, de posicionarse en una trayectoria todavía indecisa entre lo rural, los polos regionales y los destinos lejanos. Se nota en todas partes el carácter precario, a menudo transitorio, de estas instalaciones, que puede acentuarse localmente con las dificultades de gobernanza - gestión de los fraccionamientos impuestos por la promoción inmobiliaria privada por una parte, consolidación de la producción de vivienda irregular, por otra- a las que les costará hacer frente a las pequeñas localidades.

\section{Referencias}

Allub, L. \& Michel, M. A. (1982). Impactos regionales de la politica petrolera en México. México: Centro de Investigación para la Integración Social.

Bey, M. (2008). Le programme social Progresa-Oportunidades au Mexique. Revue Tiers Monde, 196(4), 881-900.

Clichevsky, N. (2008). Regularización y prevención de la irregularidad del suelo urbano. En A. Iracheta \& S. Medina (Eds.), Irregularidad y suelo urbano: ¿Cómo incidir en las prácticas y hacia dirigir las politicas públicas en México para enfrentar dicho fenómeno? (pp. 69122). México: El Colegio Mexiquense. Del Rey, A., Quesnel, A. \& Canales, A. (2006). Migración interna y migración internacional en las estrategias familiares de reproducción. El caso de las poblaciones rurales del sur del Estado de

Aurélia Michel, ANTONine Ribardière 
Veracruz, México. En A. Canales (Ed.) Panorama Actual de Las Migraciones En América Latina (pp. 426-446). Guadalajara: Universidad de Guadalajara \& Asociación Latinoamericana de Población.

Garrocho, C. (2013). Dinámica de las ciudades de México en el siglo XXI: cinco vectores clave para el desarrollo sostenible. México: Consejo Nacional de Población.

Instituto Nacional de Estadística, Geografía e Informática. (1990). Censo general de Población y Vivienda.

Instituto Nacional de Estadística, Geografía e Informática. (2000). Censo general de Población y Vivienda.

Instituto Nacional de Estadística, Geografía e Informática. (2010). Censo general de Población y Vivienda.

Perraudin, A. (2013). «Chilangos» et «campesinos», la migration internationale des Indiens depuis les villes mexicaines. Revue interdisciplinaire de travaux sur les Amériques (RITA), (6). Recuperado de http://www.revue-rita.com/villeset-campagnes/anna-perraudin.html
Quesnel, A., Saavedra, F. \& Tallet, B. (Ed.). (2012). Recomposiciones territoriales en el istmo de Tehuantepec, México: dinámica de poblamiento, movilidad y sistemas de actividades en el sur de Veracruz. México: CIESAS.

Rodríguez, H., Palma, R., Quesnel, A., Velasquez, E. \& Chazaro, G. (2013). Redistribución demográfica, nuevos patrones de pobreza en la geografía veracruzana. Proyecto FOMIX-COVECrT: Xalapa: CIESAS Golfo.

Sobrino, J. (2010). Migración interna en México durante el siglo $X X$. México: Consejo Nacional de Población.

Souchaud, S. \& Prévôt-Schapira, M-F. (2014). Transitions métropolitaines en Amérique latine: densification, verticalisation, étalement. Problèmes d'Amérique latine, 90(3), 5-16.

Valette, J-F. (2014). La régularisation territoriale des quartiers populaires de Mexico: une approche des rapports de pouvoir dans la maturation des périphéries. En J-L. Chaléard (Ed.), Métropoles aux Suds. Le défi des périphéries? (pp. 369-384). París: Khartala. 
